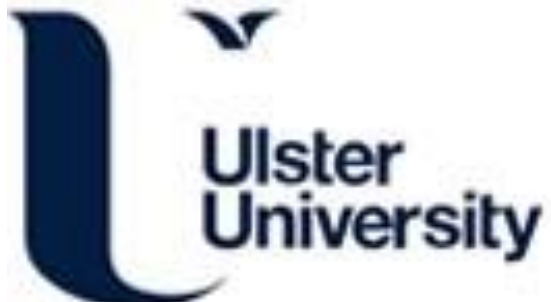

\section{The effect of fibre sizing on the modification of basalt fibre surface in preparation for bonding to polypropylene}

Ralph, C., Lemoine, P., Boyd, A., Archer, E., \& Mcllhagger, A. (2019). The effect of fibre sizing on the modification of basalt fibre surface in preparation for bonding to polypropylene. Applied Surface Science, 475 , 435-445. https://doi.org/10.1016/j.apsusc.2019.01.001

Link to publication record in Ulster University Research Portal

\section{Published in:}

Applied Surface Science

Publication Status:

Published (in print/issue): 01/05/2019

DOI:

10.1016/j.apsusc.2019.01.001

\section{Document Version}

Author Accepted version

\section{General rights}

Copyright for the publications made accessible via Ulster University's Research Portal is retained by the author(s) and / or other copyright owners and it is a condition of accessing these publications that users recognise and abide by the legal requirements associated with these rights.

\section{Take down policy}

The Research Portal is Ulster University's institutional repository that provides access to Ulster's research outputs. Every effort has been made to ensure that content in the Research Portal does not infringe any person's rights, or applicable UK laws. If you discover content in the Research Portal that you believe breaches copyright or violates any law, please contact pure-support@ulster.ac.uk. 


\title{
The effect of fibre sizing on the modification of basalt fibre surface in preparation for bonding to polypropylene
}

\author{
Calvin Ralph ${ }^{1}$, Patrick Lemoine ${ }^{1}$, Adrian Boyd ${ }^{1}$, Edward Archer $^{1}$, Alistair Mcllhagger ${ }^{1}$ \\ ${ }^{1}$ School of Engineering, Ulster University, UK
}

\section{Corresponding Author:}

Calvin Ralph, School of Engineering, Ulster University, Shore Road, Newtownabbey, BT37 OQB, UK

Email: ralph-c@ulster.ac.uk

\section{Abstract}

In this study, the effect of fibre sizing on the modification of basalt fibres in preparation for use with a polypropylene matrix (PP) was investigated. Fibres were coated by the manufacturer with a standard available epoxy (EP) sizing and four experimental PP focused sizings (PPs1-4). Fibre with no sizing was produced to act as a control. The surface topography of sized fibre was analysed by SEM and AFM, indicating that PP sized fibres displayed a more inhomogeneous coating of the fibre. Furthermore, PP sizing resulted in an increase in AFM measured roughness by $\sim 360 \%$, translating to a $12.5 \%$ increase in surface area, over both unsized and EP fibres. Scratching of the fibre surface revealed, that in general, the coating thickness of PP was 30nm thicker than EP sizing despite the same application parameters. XPS revealed that the sizing in all cases adhered to the fibre surface with an increase in potential reactive sites present on PP sized fibres. Analysis of fibre surface energy showed that the overall surface energy of fibres remained similar but the use of PP focused sizing resulted in a decrease of the polar component. Overall, this investigation shows that sizing has a significant effect on the fibre's surface: changing its topography and chemistry and hence, has an evident potential for increased mechanical and chemical bonding. This was further confirmed by single fibre fragmentation testing which highlighted that sizings PPs2-4 increase the interfacial shear strength by up to $117 \%$ compared to non-sized fibres.

\section{Keywords}

Basalt fibre, Sizing, Thermoplastics, Surface properties, Surface analysis 


\section{Introduction}

Natural fibres are gaining significant attention as reinforcement for polymer composites due to their reduced environmental impacts. Among natural fibres, basalt fibres demonstrate superior mechanical properties compared to vegetal fibres and compare, or are higher, to those of glass [1-3]. The density of basalt is between $2.6-2.7 \mathrm{~g} / \mathrm{cm} 3$ whereas E-Glass density is $2.5-2.6 \mathrm{~g} / \mathrm{cm} 3$ [4]. Basalt fibres are further characterised by excellent sound insulation, thermal resistance higher than that of glass, good chemical resistance to both acidic and alkaline conditions (higher than E-glass) and biologically inert [5-7]. These factors, together with its environmentally friendly nature, mean it displays significant potential as a competitor or replacement of glass fibres and a new fibre for various applications. As a result basalt fibres have been the focus of recent research with an aim to identify their potential applications $[4,7-13]$

In recent years, particular attention has been paid to thermoplastic matrices due to their low cost, good mechanical properties and recyclability with studies showing the potential of basalt fibre thermoplastics over glass $[4,10,14]$. However, it has been demonstrated that in order to achieve efficient reinforcement of thermoplastics, adhesion between basalt fibre and the thermoplastic matrix needs to be improved. Any load applied to a composite is transferred through the polymer matrix to the fibre via the fibre-matrix interface. Consequently, this interface region is a crucial factor in determining the ultimate properties of the composite. Improved adhesion can be achieved through surface modification of the fibre through application of a 'sizing', chemical or plasma treatment $[15,16]$ or, through bulk modification of the matrix by the inclusion of various compatibilisers such as maleic anhydride grafted polypropylene (PPgMA) [10,14]. Fibre sizing is a fundamental stage during the manufacture of basalt fibre and hence remains one of the simplest and most cost effect methods for promoting adhesion. Sizing is a multi-purpose coating which accounts for $0.2-5 \%$ of the fibre weight and due to the nature of application, is frequently non uniform. The sizing consists of various processing aids such as antistatic agent, wetting agent, lubricants and binders $[2,17,18]$, however, it is unknown what affect these have on the fibre-matrix interface. The primary component of fibre sizing is the coupling agent, typically silanes, which is designed to chemically bond and react with both the fibre surface and matrix and is a crucial factor in 
determining the level of adhesion [2,4,14,17-21]. This is particularly important for a thermoplastic such as PP where the non-polar matrix is not naturally attracted to the polar basalt fibre, proving to be an important technical challenge. Research to date has heavily focused on improving this BF-PP interface through modification of the polymer or surface treatment of basalt fibre, all of which require additional processes and thus increasing the cost of the resulting composite. Fibre sizing has already demonstrated a high ability to improve adhesion between glass/carbon and thermosets and thermoplastics [22-25]. The increased interest in thermoplastic matrices such as polypropylene has been identified by fibre manufacturers and as such there are an increasing number of manufacturers developing sizing designed for use with polypropylene. Therefore, it is the aim of this study to investigate the effect these fibre sizings have on the modification of basalt fibres and how this prepares them for bonding to PP matrices.

\section{Materials and methods}

\subsection{Materials}

Basalt fibre for reinforcement was provided by Mafic, Ireland. All fibres tested were direct roving $13 \mu \mathrm{m}$ nominal diameter and 300tex. Fibre was provided non-sized (labelled $-\mathrm{N}$ ) and surface modified with standard multi-purpose sizing typically used for epoxy systems (EP). A further four experimental sizings developed by Mafic for use with polypropylene (PP) resin systems were used. These were designated PPs1, PPs2, PPs3 and PPs4. All sizings were applied during manufacture of the fibre. Non-sized fibres were manufactured in the normal manor except with the omission of the sizing process where no sizing was applied. De-ionised water was used for the cooling of these fibres.

\subsection{Methods}

\subsubsection{Scanning electron microscopy}

The effect of sizing on fibre surface topography was investigated using a Scanning Electron Microscope(SEM)(JEOL JSM-6010). All fibre samples were gold coated prior to imaging to prevent charging and to increase image quality. 


\subsubsection{Atomic Force Microscopy}

Atomic Force Microscopy (AFM) was carried out using a VEECO DI 3100 Scanning Probe Microscope system. AFM was performed in two modes. Tapping mode was used to characterise the surface topography at a frequency of $1 \mathrm{~Hz}$ with a TESP $(n)$ doped silicon tip (stiffness $\sim 40 \mathrm{Nm}^{-1}, \sim 274-386 \mathrm{kHz}$ resonance frequency). Contact mode (CAFM) at high load was used for scratching the fibre surface to measure sizing thickness and failure mode at a scanning rate of $1 \mathrm{~Hz}$ with a nano-crystalline diamond coated tip (stiffness $\sim 2.8 \mathrm{Nm}^{-1}$, tip radius $\sim 10 \mathrm{~nm}$ and $\sim 65 \mathrm{kHz}$ resonant frequency). Fibres where imaged and measured using tapping mode both before and after scratching. All scratched areas are $10 \times 5 \mu \mathrm{m}$, while imaged areas are $20 \times 10 \mu \mathrm{m}$. Non-sized fibres were initially tested at various loads to determine the maximum scratching force without damaging the fibre surface.

\subsubsection{X-ray photoelectron spectroscopy}

The chemical composition and functional groups on the surface of sized and non-sized basalt fibre was investigated using a high resolution X-Ray photoelectron spectrometer (Kratos Axis Ultra DLD) with a monochromatic aluminium Ka source $(1486.6 \mathrm{eV})$, operating at a pressure of $8 \times 10^{-9}$ torr. Spot area of $300 \mu \mathrm{m} \times 700 \mu \mathrm{m}$ was analysed with a pass energy of $160 \mathrm{eV}$ and 20 $\mathrm{eV}$ for survey and high resolution scans with three spots scanned per sample. Charging effects on the surface of samples was rectified by calibrating the lowest component of the spectral envelope of the $\mathrm{C} 1 \mathrm{~s}$ peaks to $285.0 \mathrm{eV}$ which is the value generally accepted for adventitious carbon. Quantification of the components was conducted using a linear background correction of basalt fibre samples [26].

\subsubsection{Dynamic contact angle}

Changes in wettability and surface energy as a result of fibre sizing were investigated by dynamic contact angle (DCA) using a Camtel CDCA-100 tensiometer with resolution of $10^{-5} \mathrm{~g}$ and surface detection set to $5 \times 10^{-5} \mathrm{~g}$. Two test liquids were used, namely water (polar) and diiodomethane (apolar). The surface tension $\gamma_{L}$, polar $\gamma_{L}^{p}$ and dispersive $\gamma_{L}^{d}$ components, density $\rho$ and viscosity $\eta$ of each liquid at room temperature are listed in Table 1 . Single fibres were clamped to the tensiometer and immersed in the test liquid at a speed of $0.1 \mathrm{~mm} / \mathrm{s}$ to a 
depth of $8 \mathrm{~mm}$ and withdrawn at the same rate to a position $-4 \mathrm{~mm}$ above the initial starting position.

The polar and dispersive components of the fibre surface energy were calculated using the Owens and Wendt equation (Eq. 1) coupled together with the contact angle determined by the Young-Laplace equilibrium (Eq. 2) [27].

$\gamma_{S}+\gamma_{L}-\gamma_{S L}=2\left(\gamma_{S}^{d} \gamma_{L}^{d}\right)^{0.5}+2\left(\gamma_{S}^{p} \gamma_{L}^{p}\right)^{0.5}$

$\gamma_{s v}=\gamma_{s l}+\gamma_{l v} \cos \theta_{\gamma}$

By using two liquids, one polar and one dispersive, the polar and dispersive components can be determined as there are two equations with two unknowns. The Owens and Wendt equation can then be written as shown in (Eq. 3). It is noted that this equation has the form of $y=m x+b$ where:

$\boldsymbol{y}=\frac{\gamma_{L}\left(1+\cos \theta_{c}\right)}{\sqrt[2]{\gamma_{L}^{d}}} ; \boldsymbol{m}=\sqrt{\gamma_{S}^{p}} ; \boldsymbol{x}=\frac{\sqrt{\gamma_{L}^{p}}}{\sqrt{\gamma_{L}^{d}}} ; \boldsymbol{b}=\sqrt{\gamma_{S}^{d}}$

The slope and the y-intercept are the square roots of the polar and dispersive components respectively.

Table 1 Properties of test liquids at room temperature

\begin{tabular}{llllll}
\hline & $\eta$ (mPas) & $\rho\left(\mathrm{g} / \mathrm{cm}^{3}\right)$ & $\gamma_{L}(\mathrm{mN} / \mathrm{m})$ & $\gamma_{L}^{p}(\mathrm{mN} / \mathrm{m})$ & $\gamma_{L}^{d}(\mathrm{mN} / \mathrm{m})$ \\
\hline Water & 1.00 & 0.998 & 72.8 & 51.0 & 21.8 \\
Diiodomethane & 2.76 & 3.325 & 50.8 & 2.3 & 48.5 \\
\hline
\end{tabular}

\subsubsection{Interfacial shear strength (IFSS)}

IFSS was tested via the single fibre fragmentation test (SFFT). Samples were prepared by compression moulding a single fibre between two thin sheets of PP. Moulding was performed between two steel tools that were heated to $190^{\circ} \mathrm{C}$ then moulded under a $20 \mathrm{MPa}$ pressure. Insitu testing was performed on a Deben micro dual leadscrew tensile stage with a crosshead speed of $0.03 \mathrm{~mm} / \mathrm{min}$. The tensile stage was mounted on an Olympus BX53 microscope equipped with an $\mathrm{X}-\mathrm{Y}$ stage and linear polarising filters which was used to perform measurements on fibre diameter and broken fragment lengths. SFFT testing was performed in accordance with Hunston et al. [28] where strain cycles of $0.2 \%$ increments were used with the 
number of breaks recorded for each cycle. Once saturation had been reached, the fragment lengths were recorded. IFFS was calculated by the Kelley and Tyson model [29] given in Eq. (4).

$\tau=\frac{\sigma_{f} d}{2 l_{c}}$

where $d$ is the fibre diameter, $l_{c}$ is the critical fibre length and $\sigma_{f}$ is the fibre strength at the critical fibre length. The critical fibre length $l_{c}$ is calculated by Eq. (5).

$l_{c}=\frac{4}{3} \bar{l}$

where $\bar{l}$ is the average fibre length. The fibre strength at the critical length was calculated by tensile testing single fibres at gauge lengths of 25,50 and $100 \mathrm{~mm}$ according to ASTM D3822 and then using Weibull analysis to predict the fibre strength at the critical fibre length.

\section{$3 \quad$ Results and discussion}

\subsection{Fibre surface}

SEM images showing topographic changes of the basalt fibre surface due to sizing are shown in Fig. 1. Significant differences are evident between non-sized and sized fibres. Fibres with no sizing $(\mathrm{N})$ are characterised by a smooth and clean surface. EP sized fibres have a similar surface with some minor features evident in the form lumps/raised areas albeit very small $(<0.5 \mu \mathrm{m})$, indication of a homogeneous coating. A significant change in fibre topography is seen with the addition of the experimental PP sizings. There is a clear visual increase in surface roughness of each PP sized fibre which is presented as large clumps, clusters and ridges of sizing on the surface. It is notable that the larger roughness features seen on the surface for all PP samples show a thick discontinuous behaviour, however, a thinner more continuous layer of coating is visible between the thicker clusters suggesting a more even coverage of the fibre sizing is also present in smaller quantities. This apparent discontinuous behaviour of polypropylene sizings may be due to the greater difficulty of wetting the polar basalt fibre with an apolar sizing [30]. 
To further investigate the influence of the different sizings on the fibre surface, AFM topographic images were obtained (Fig. 2). These images reinforce the findings of SEM where $\mathrm{N}$ and EP fibres result in a smooth and continuous surface with PP sized fibres showing a considerable increase in surface features and roughness. This roughness has been measured via AFM for both RMS and Ra calculations and is presented in Fig. 3. From these values we can see that EP sized fibres interestingly have a lower surface roughness than non-sized fibre. This may be explained by the EP sizing filling in small imperfections on the natural fibre's surface and thus creating a smoothing effect. It is clear from roughness values that PP focused sizing causes a considerable increase in surface roughness. PPs1 provides the lowest increase yet it still has a roughness $\sim 133 \%$ higher than $\mathrm{N}$ fibres. The roughness increases again by approximately $360 \%$ for fibres PPs2, PPs3 and PPs4 over fibres with no sizing. This increase in roughness has a direct effect on fibre surface area which is a primary factor in determining mechanical interlocking. Surface area measurements (Fig.3) show that PPs2-4 provides the greatest increase in surface area from $52.5 \mu \mathrm{m}^{2}$ to $\sim 58.9 \mu \mathrm{m}^{2}$. This higher level of surface roughness and area may result in increased mechanical interlocking between the fibre and matrix, resulting in a positive influence on the mechanical properties of final composite [31,32]. As PPs2-4 each provide a similar increase in roughness and surface are they should provide the same level of mechanical interlocking, hence, it can be suggested that any variation in adhesion between these three sizings may be attributed to variations in chemical bonding.

Post scratch AFM images and the resulting scratch depth profile of non-sized and sized fibres are presented in Fig.4. Scratching of the fibre surface can determine two main properties of the sizing: thickness and failure mode. Although $\mathrm{N}$ fibres show a scratched area, this observed build up is a result of surface contamination from the atmosphere, such as dust, which is confirmed by the scratch depth scan showing zero/no trench profile. Although all sizing formulations were applied with the same loss of ignition (LOI) there is a significant difference in overall thickness of the coating. Sizing EP and PPs1 have a thin coating of $\sim 10-20 \mathrm{~nm}$ that appears continuous, in agreement with SEM and AFM images (Fig. 1 and Fig. 2). As the sizing is scratched or 'ploughed' it displays a ductile failure behaviour evident by the continuous build up of sizing at the edges of the scratch, this is seen as bright yellow colouring around the perimeter of the scratched area in Fig. 4. On the other hand sizing PPs3 displayed a very brittle nature with 
clumps or fragments of sizing being dislodged due to scratching method making it difficult to measure which is confirmed by the respective scratch profile where there is no clear trench and an inconsistent depth. The overall thickness of PPs3 sizing was recorded to be between $~ 30-$ $40 \mathrm{~nm}$. Sizing PPs2 and PPs4 had a similar ductile behaviour as EP and PPs1 but was measured with an increased thickness of $\sim 40-50 \mathrm{~nm}$. The increased thickness recorded for sizing PPs2, PPs3 and PPs4 may further contributed to the higher levels of measured surface roughness. Although it is unknown the effect sizing thickness has on the fibre/matrix interface it is thought that a thicker sizing creates a higher bonding potentially both mechanically via increased surface roughness and chemically via the potential of an increased number of reactive sites present on the surface $[32,33]$.

\subsection{XPS}

XPS analysis was conducted to investigate the chemical changes on the basalt fibre surface as a result of fibre sizing. The surface composition results from wide energy survey scans and calculated ratios are reported in Table 2 .

Table 2 XPS atomic concentration \% and ratios of basalt fibre samples

\begin{tabular}{lllllll}
\hline Fibre & $\mathrm{C}(\%)$ & $\mathrm{O}(\%)$ & $\mathrm{Si}(\%)$ & $\mathrm{N}(\%)$ & $\mathrm{O} / \mathrm{C}$ & $\mathrm{C} / \mathrm{Si}$ \\
\hline $\mathrm{N}$ & 55.85 & 33.45 & 10.73 & - & 0.6 & 5.21 \\
$\mathrm{EP}$ & 78.47 & 20.03 & 1.68 & - & 0.26 & 52.31 \\
$\mathrm{PPs} 1$ & 77.13 & 18.66 & 2.82 & 1.48 & 0.24 & 27.35 \\
PPs2 & 71.55 & 21.87 & 6.59 & 1.6 & 0.31 & 10.86 \\
PPs3 & 81.13 & 14.7 & 3.49 & 1.12 & 0.18 & 23.25 \\
PPs4 & 76.39 & 21.01 & 2.6 & - & 0.28 & 29.38 \\
\hline
\end{tabular}

It has been shown that the $\mathrm{C} / \mathrm{Si}$ ratio can be used as an initial approximation for the level of organic material where a ratio of $\mathrm{C} / \mathrm{Si}$ greater than 10 indicates the XPS signal is dominated by the fibre sizing and below 10 is dominated by the fibre substrate [34]. The penetration depth of XPS is $<10 \mathrm{~nm}$, however, as the measured thickness for all sizings is between $10-50 \mathrm{~nm}$ it indicates that the signal is dominated by the sizing regardless of $\mathrm{C} / \mathrm{Si}$ ratio. For all sized fibres we can see the C content increase by $\sim 20-25 \%$ and $O$ content drop to $\approx 20 \%$ compared to $33.45 \%$ for non-sized fibre which translates to the $\mathrm{O} / \mathrm{C}$ ratio. The reduction of the $\mathrm{O} / \mathrm{C}$ ratio of sized fibres compared to non-sized indicates that the silane coupling agent has attached to the 
basalt fibre surface $[35,36]$. High resolution analysis was performed on the main peaks found which were curve fitted to determine the functional groups present.

The C1s spectra of unsized and sized basalt fibres is shown in Fig. 5. Although basalt fibres do not contain carbon, $55.85 \%$ of the non-sized fibre surface contained carbon bonds. The C1s spectra of $\mathrm{N}$ samples can be divided into three peaks at $285 \mathrm{eV}, 286.6 \mathrm{eV}$ and $289 \mathrm{eV}$ representing $\mathrm{C}-\mathrm{C}, \mathrm{C}-\mathrm{O}-\mathrm{C}$ and $\mathrm{O}=\mathrm{C}-\mathrm{O}$, characteristic of adventitious carbon. Peak fitting of EP sized fibres identifies two main peaks; the first at $285 \mathrm{eV}$ is attributed to $\mathrm{C}-\mathrm{C}$ where the second peak at 286.7 is quite broad and may be attributed to C-O and C-O-C, in agreement with epoxy functional groups [37]. Sized fibres PPs1, PPs3 and PPs4 showed a significant increase in C-C compared to $\mathrm{N}$ and EP fibres whereas PPs2 showed a significant decrease in C-C content. The second largest functional group in PP sized fibres was found at $286.5 \mathrm{eV}$ and was attributed to $\mathrm{C}-\mathrm{O} / \mathrm{C}-\mathrm{OH}$. These hydroxyl groups have shown to play an important role in bonding with thermoplastics [38]. PPs2 has more than double the content of $\mathrm{C}-\mathrm{O} / \mathrm{C}-\mathrm{OH}$ groups compared to the remaining PP sized fibres, suggesting there may be an increased bonding environment present.

The $01 \mathrm{~s}$ spectra of basalt fibre can be divided into two peaks, at $531.9 \mathrm{eV}$ and $533.4 \mathrm{eV}$ seem in Fig. 6. These peaks are in agreement with non-bridging oxygen (NBO) and bridging oxygen (BO) in the silicate structure [39]. The division of NBO and BO appears to vary between each fibre (Table 3). Fibres with no sizing N were dominated by NBO while EP sized fibres predominantly consisted of BO. Between these two were PP sized fibres which indicated a more balanced division between NBO and $\mathrm{BO}$. The significant increase of $\mathrm{BO}$ found on sized fibres compared to non-sized fibre may be attributed to the silanol groups present within the sizing formulation. These groups are added in order for the sizing to react quickly with the fibre surface, hence may present as Si-O-Si chains.

The Si $2 p$ spectra for sized and non-sized fibre are shown in Fig. 7. As the Si $2 p$ spectra is dependent on the silicate content the same peak representing $\left[\mathrm{SiO}_{4}\right]^{4-}$ tetrahedron structure was observed at ca. $101.7 \mathrm{eV}$ and $101.8 \mathrm{eV}$ for non-sized and sized fibres. A further two peaks can be observed in the Si $2 p$ spectra which represent $\left[\mathrm{Si}_{2} \mathrm{O}_{5}\right]^{2-}$ (layer shape structure) and $\left[\mathrm{Si}_{2} \mathrm{O}_{6}\right]^{4-}$ (chain structure), in accordance with Furukawa et al. [40] and Wang et al. [41]. The peak observed at $\sim 102.6 \mathrm{eV}$ for all samples can be attributed to the layer shape structure of 
$\left[\mathrm{Si}_{2} \mathrm{O}_{5}\right]^{2-}$. A new peak at a higher binding energy of $103.8 \mathrm{eV}$ can be observed in the $\mathrm{Si} 2 \mathrm{p}$ spectra of PPs2 $(2.24 \%)$ and in trace amounts for PPs3 $(0.57 \%)$ and EP $(0.33 \%)$ fibre. This new peak is assumed to be $\left[\mathrm{Si}_{2} \mathrm{O}_{6}\right]^{4-}$ chain structure. Despite all sizings containing silanol groups, EP samples have shown to have the lowest content of silicon on the fibre surface at 1.5\% (Table 2). As the sizing becomes more targeted for thermoplastics the silicon content increases, peaking at $6.59 \%$ for PPs2 suggesting higher levels of silane. With the purpose of silanol groups within the sizing to promote adhesion to the fibre, it may indicate that there is increased bonding between the sizing and the fibre surface for PPs1-4 samples [35]. Although $\left[\mathrm{SiO}_{4}\right]^{4-}$ within PPs1 and PPs2 is comparable at $0.99 \%$ and $1.25 \%$ (Table 3), there is a significant increase in $\left[\mathrm{Si}_{2} \mathrm{O}_{5}\right]^{2-}$ in PPs2 with a $3.06 \%$ content compared to $1.71 \%$ for PPs1. The addition of $\left[\mathrm{Si}_{2} \mathrm{O}_{6}\right]^{4-}$ bonds at $2.24 \%$ concentration present with in PPs2 samples further suggests increased bonding between sizing and fibre surface.

Table $3 \mathrm{Si} 2 \mathrm{p}$ andO1s functional group \% for non-sized and sized fibres

\begin{tabular}{lllllll}
\hline $\begin{array}{l}\text { Functional } \\
\text { Group }\end{array}$ & $\mathrm{N}(\%)$ & $\mathrm{EP}(\%)$ & PPs1 (\%) & PPs2 (\%) & PPs3 (\%) & PPs4 (\%) \\
\hline$\left[\mathrm{SiO}_{4}\right]^{4-}$ & 2.40 & 0.21 & 0.99 & 1.25 & 0.88 & 1.68 \\
{$\left[\mathrm{Si}_{2} \mathrm{O}_{5}\right]^{2-}$} & 6.95 & 0.90 & 1.71 & 3.06 & 1.88 & 1.22 \\
{$\left[\mathrm{Si}_{2} \mathrm{O}_{6}\right]^{4-}$} & - & 0.57 & - & 2.24 & 0.72 & - \\
$\mathrm{NBO}$ & 28.57 & 0.98 & 8.22 & 9.60 & 9.47 & 11.27 \\
$\mathrm{BO}$ & 3.01 & 18.84 & 11.19 & 12.78 & 5.05 & 9.57 \\
\hline
\end{tabular}

Fibre samples PPs1-3 contained small quantities of $\mathrm{N} 1 \mathrm{~s}$, which were divided in to two peaks. As presented in Fig. 8. , these were divided by an amine with a low-binding energy (399.8 eV) and an amine with a high-binding energy $(401.2 \mathrm{eV})$. This content of $\mathrm{N}$ may be evidence of aminosilane found in sizing and may be suggestive of an increased bonding environment [42].

\subsection{Fibre surface energy}

Advancing and receding contact angles of single basalt fibres tested in water and diiodomethane are plotted in Fig. 9. With all contact angles for both liquids being less than $90^{\circ}$ it can be said that each fibre sample becomes fully wet by both water and diiodomethane.

Deviation bars show that PP focused sizing generally has a greater variation. The cause for this is most likely due to the homogeneity of EP coated fibres and thus resulting in improved reproducibility whereas the increased roughness and visible residue, from SEM and AFM, on the surface of PP sized fibres will affect static angle measurements. The application of EP and 
PPs1 sizing results in a small reduction in contact angle in water while PPs2, PPs3 and PPs4 show a small increase of $\sim 1.5-2$ degrees in angle over $\mathrm{N}$ fibre. In diiodomethane the behaviour is opposite to this where PPs2, PPs3 and PPs4 show a marked decrease in contact angle over EP and PPs1 sizing. This may indicate that the polar and dispersive functions of these sizings differ.

Surface energies of non-sized and sized basalt fibres calculated from the Owens and Wendt equation (Eq. 3) are summarised in Table 4. Although there is no significant change in the overall surface energy of the fibre there is a more notable shift in the polar and dispersive components. EP fibres show a slight increase of $\sim 1.5 \mathrm{mN} / \mathrm{m}$ over non-sized fibre which will increase the compatibility and bonding with polar epoxy systems [43]. EP and PPs1 sized fibres have a similar polar and dispersive component as non-sized fibre which is suitable for a polar epoxy matrix system but inherently not for non-polar PP [43]. We can see that sizings PPs2, PPs3 and PPs4 all reduce the polar component of the fibre surface by $14-25 \%$ compared to N, EP and PPs1 fibres, with PPs2 providing the largest decrease at 25\%. This reduced polar component of the fibre surface increases it's compatibility with PP and thus may improve fibre wetting and in turn bonding. Previous studies have shown that silanization decreases the polar surface energy of glass fibres [44,45], as such the suggested increased silane content from the XPS Si $2 p$ spectra of PP sized fibres can be attributed with their reduced polar component.

Table 4 Polar and dispersive components and the total surface energy of non-sized and sized basalt fibre

\begin{tabular}{llll}
\hline Fibre & $Y_{s}^{p}(\mathrm{mN} / \mathrm{m})$ & $Y_{s}{ }^{d}(\mathrm{mN} / \mathrm{m})$ & $Y_{s}^{p}(\mathrm{mN} / \mathrm{m})$ \\
\hline $\mathrm{N}$ & $15.36 \pm 0.31$ & $27.47 \pm 0.28$ & $42.83 \pm 0.59$ \\
EP & $16.68 \pm 1.08$ & $28.94 \pm 0.76$ & $44.62 \pm 1.84$ \\
PPs1 & $15.71 \pm 0.83$ & $26.11 \pm 0.75$ & $41.82 \pm 1.58$ \\
PPs2 & $11.51 \pm 0.60$ & $32.44 \pm 0.61$ & $43.95 \pm 1.21$ \\
PPs3 & $13.22 \pm 0.69$ & $30.26 \pm 1.12$ & $43.48 \pm 1.81$ \\
PPs4 & $12.99 \pm 0.25$ & $30.75 \pm 0.57$ & $43.73 \pm 0.82$ \\
\hline
\end{tabular}

\subsection{Interfacial shear strength}

The critical length, tensile strength at the critical length and the resultant IFSS values of each fibre are reported in Table 5. EP and PPs1 fibres have an IFSS significantly lower than nonsized $\mathrm{N}$ fibre, suggesting that a very poor adhesion is present. PPPs3 and PPs4 sized fibres 
show a considerable increase over N fibres with an IFSS of 14.48 and $13.03 \mathrm{MPa}$ respectively. A significant increase is further seen for PPs2 sized fibre with an IFSS of $20.68 \mathrm{MPa}$, a $117.6 \%$ increase over fibres with no sizing. This increase in adhesion will promote the efficient transfer of stress between the matrix and fibre [46]. Mechanical interlocking may have contributed to a certain degree, however the small variation in measured values of surface roughness and surface area does not reflect accurately the differences in IFSS.

Table 5 Critical length, tensile strength at critical length and IFSS of all fibres from SFFT testing

\begin{tabular}{llll}
\hline & $\mathrm{I}_{\mathrm{c}}(\mathrm{mm})$ & $\sigma_{\mathrm{f}}\left(\mathrm{l}_{\mathrm{c}}\right)(\mathrm{MPa})$ & $\mathrm{T}(\mathrm{MPa})$ \\
\hline $\mathrm{N}$ & $1.80 \pm 0.10$ & 2615 & $9.50 \pm 0.56$ \\
EP & $2.22 \pm 0.29$ & 2561 & $7.59 \pm 0.92$ \\
PPs1 & $3.15 \pm 0.45$ & 2488 & $5.21 \pm 0.79$ \\
PPs2 & $0.89 \pm 0.09$ & 2784 & $20.68 \pm 2.11$ \\
PPs3 & $1.23 \pm 0.15$ & 2698 & $14.48 \pm 2.09$ \\
PPs4 & $1.36 \pm 0.18$ & 2663 & $13.02 \pm 1.71$ \\
\hline
\end{tabular}

Fibre polarity will influence potential bonding as the reduced polarity of PPs2, PPs3 and PPs4 fibres will improve compatibility between the fibre and PP as well as improve fibre wet-out, thus increasing the potential area for bonding. Although each of these factors will contribute to adhesion it is believed that chemical bonding is the primary factor in improving the IFSS and the variations observed between each sizing due to the increased reactive sites evident on PPs3, PPs4 and in particular PPs2.

Adhesion of basalt fibre to PP show to be higher than glass fibre equivalents which range between 3.5 to $5 \mathrm{MPa}$ for unsized and 6 to $7.5 \mathrm{MPa}$ for sized fibre [23,47]. Results from PPs2, PPs3 and PPs4 produce a similar or greater, in the case of PPs2, improvement in adhesion properties compared to bulk modification of PP with PP-g-MA [14]. Furthermore, the results for PPs2 are comparable to sized carbon fibre and epoxy [48].

\section{Conclusions}

The focus of this study was to investigate the effect of fibre sizing on basalt fibre surface in preparation for use with a polypropylene matrix. Fibres were coated in a standard available epoxy sizing, four different experimental polypropylene focused sizings and compared to fibres with no sizing. The surface topography of basalt fibre has been analysed by SEM and AFM which indicates that PP sizings have a more inhomogeneous coating. It was revealed that epoxy sizing reduces the roughness of the basalt fibre surface while a considerable increase in 
surface roughness was evident with PP sizing, leading to an increased surface area which may be beneficial for mechanical bonding. Furthermore, the use of PP focused sizing resulted in a much thicker coating on the fibre surface despite using the same application parameters and Loss of Ignition. The use of fibre sizing has shown to modify the surface chemistry of basalt fibres with XPS confirming that the sizing has adhered to the fibre surface and the addition of potential reactive sites or increased bonding environment for PP. Fibre sizing has also shown to influence the surface energy of fibre where the use of PP focused sizing results in lowering of the polar component of basalt fibre and thus increasing its compatibility and wetting properties with non-polar PP. Overall, sizing has shown to have a significant influence on the surface of basalt fibres with both EP and PP focused sizings providing a different set of characteristics. PP focused sizings have modified the fibre surface in such a way to increase the fibres compatibility and wetting with PP as well as increased its bonding potential both mechanically and chemically. These results were further confirmed with IFSS testing showing that adhesion between basalt and PP can be significantly increased through the use of a focused sizing, with fibres that demonstrated increased reactive sites having a significantly higher IFSS. The resultant improvements in adhesion properties highlighted that fibre sizing, in most cases, provided a greater increase than bulk modification of PP with PP-g-MA.

\section{Acknowledgement}

The authors would like to thank Ulster University, Northern Ireland Advanced Composites and Engineering (NIACE) Centre and Axis Composites for support and provision of testing equipment and Mafic SA Basalt for the provision of materials, development and application of fibre sizing.

\section{Funding}

This work was supported and funded by a Department for Employment and Learning (DEL) CAST award.

Declarations of interest: none 


\section{References}

[1]Fiore V, Scalici T, Di Bella G, Valenza A. A review on basalt fibre and its composites. Composites Part B: Engineering 2015;74:74-94.

[2] Ku H, Wang H, Pattarachaiyakoop N, Trada M. A review on the tensile properties of natural fiber reinforced polymer composites. Composites Part B: Engineering 2011 6;42(4):856-873.

[3]Djafari Petroudy SR. 3 - Physical and mechanical properties of natural fibers. In: Fan M, Fu F, editors. Advanced High Strength Natural Fibre Composites in Construction: Woodhead Publishing; 2017. p. 59-83.

[4]Czigány T. Special manufacturing and characteristics of basalt fiber reinforced hybrid polypropylene composites: Mechanical properties and acoustic emission study. Composites Sci Technol 2006 12/18;66(16):3210-3220.

[5]Landucci G, Rossi F, Nicolella C, Zanelli S. Design and testing of innovative materials for passive fire protection. Fire Saf J 2009 11;44(8):1103-1109.

[6]Wei B, Cao H, Song S. Environmental resistance and mechanical performance of basalt and glass fibers. Materials Science and Engineering: A 2010 7/15;527(18-19):4708-4715.

[7]Liu Q, SHaw MT, Parnas RS. Investigation of Basalt Fiber Composite Mechanical Properties for Applications in Transportation. Polymer Composites 2006;27(1):41-48.

[8]Chlup Z, Černý M, Strachota A, Hadraba H, Kácha P, Halasová M. Effect of the exposition temperature on the behaviour of partially pyrolysed hybrid basalt fibre composites. Composites Part B: Engineering 201815 August 2018;147:122-127.

[9]Bhat T, Chevali V, Liu X, Feih S, Mouritz AP. Fire structural resistance of basalt fibre composite. Composites Part A: Applied Science and Manufacturing 2015 4;71:107-115.

[10]Botev M, Betchev H, Bikiaris D, Panayiotou C. Mechanical Properties and Viscoelastic Behavior of Basalt Fiber-Reinforced Polypropylene. Journal of Applied Polymer Science 1999;74:523-531.

[11]Fiore V, Scalici T, Badagliacco D, Enea D, Alaimo G, Valenza A. Aging resistance of bioepoxy jute-basalt hybrid composites as novel multilayer structures for cladding. Composite Structures 201715 January 2017;160:1319-1328.

[12]Scalici T, Fiore V, Valenza A. Experimental assessment of the shield-to-salt-fog properties of basalt and glass fiber reinforced composites in cork core sandwich panels applications. Composites Part B: Engineering 20181 July 2018;144:29-36.

[13]Yasir M, Amir N, Ahmad F, Ullah S, Jimenez M. Effect of basalt fibers dispersion on steel fire protection performance of epoxy-based intumescent coatings. Progress in Organic Coatings 2018 September 2018;122:229-238.

[14]Greco A, Maffezzoli A, Casciaro G, Caretto F. Mechanical properties of basalt fibers and their adhesion to polypropylene matrices. Composites Part B: Engineering 2014 12;67(0):233238.

[15]Kim MT, Kim MH, Rhee KY, Park SJ. Study on an oxygen plasma treatment of a basalt fiber and its effect on the interlaminar fracture property of basalt/epoxy woven composites.

Composites Part B: Engineering 2011 4;42(3):499-504. 
[16]Manikandan V, Winowlin Jappes JT, Suresh Kumar SM, Amuthakkannan P. Investigation of the effect of surface modifications on the mechanical properties of basalt fibre reinforced polymer composites. Composites Part B: Engineering 2012 3;43(2):812-818.

[17]Lopresto V, Leone C, De lorio I. Mechanical characterisation of basalt fibre reinforced plastic. Composites Part B: Engineering 2011 6;42(4):717-723.

[18]AL-Oqla FM, Sapuan SM. Natural fiber reinforced polymer composites in industrial applications: feasibility of date palm fibers for sustainable automotive industry. J Clean Prod 2014 3/1;66(0):347-354.

[19]Arbelaiz A, Fernández B, Ramos JA, Retegi A, Llano-Ponte R, Mondragon I. Mechanical properties of short flax fibre bundle/polypropylene composites: Influence of matrix/fibre modification, fibre content, water uptake and recycling. Composites Sci Technol 2005 8;65(10):1582-1592.

[20]Gassan J, Bledzki A. Thermal degradation of flax and jute fibers. Journal od Applied Polymer Science $2001 ; 82(6): 1417-1422$.

[21]Bashtannik PI, Kabak AI, Yakovchuk YY. The effect of adhesion interaction on the mechanical properties of thermoplastic basalt plastics. Mechanics of Composite Materials 2003;39(1):85-88.

[22]Zhao FM, Takeda N. Effect of interfacial adhesion and statistical fiber strength on tensile strength of unidirectional glass fiber/epoxy composites. Part I: experiment results. Composites Part A: Applied Science and Manufacturing 2000 November 2000;31(11):1203-1214.

[23]Etcheverry M, Ferreira ML, Capiati NJ, Pegoretti A, Barbosa SE. Strengthening of polypropylene-glass fiber interface by direct metallocenic polymerization of propylene onto the fibers. Composites Part A: Applied Science and Manufacturing 2008 December 2008;39(12):1915-1923.

[24]Dilsiz N, Wightman JP. Surface analysis of unsized and sized carbon fibers. Carbon 1999;37(7):1105-1114.

[25]Dilsiz N, Wightman JP. Effect of acid-base properties ofsized carbon fibers on fiber/epoxy matrix adhesion. In: Reifsnider KL, Dillard DA, Cardon H, editors. Progress in durability analysis of Composite systems Rotterdam: A.A Balkema; 1998. p. 309-318.

[26]ASTM Guide E1523. Standard guide to charge control and charge referencing techniques in x-ray photoelectron spectroscopy. 2003.

[27]Owens DK, Wendt RC. Estimation of the surface free energy of polymers . Journal of Applied Polymer Science 1969;13(8):1741-1747.

[28]Hunston D, McDonough W, Holmes G, Parnas R, Drzal L, Rich M. Test protocol for singlefiber fragmentation test - International round robin.

[29]Kelley A, Tyson W. Tensile properties of fiber-reinforced metals. J Mech Phys Solids 1965;13:329-350.

[30]Thomason JL, Schoolenberg GE. An investigation of glass fibre/polypropylene interface strength and its effect on composite properties. Composites 1994 March 1994;25(3):197-203.

[31]Nematollahzadeh A, Mousavi SA, Tilaki RM, Frounchi M. Increasing the Interfacial Adhesion in Poly(methyl methacrylate)/Carbon Fibre Composites by Laser Surface Treatment. Polymers \& Polymer Composites 2006;14(6):585-589. 
[32]Yao Y, Chen S. The effects of fiber's surface roughness on the mechanical properties of fiber-reinforced polymer composites. Journal of Composite Materials 2013;47(23):2909-2923.

[33]Katainen J, Paajanen M, Ahtola E, Pore V, Lahtinen J. Adhesion as an interplay between particle size and surface roughness. Journal of Colloid and Interface Science 2006;304:524529.

[34]Thomason JL. The interface region in glass fibre-reinforced epoxy resin composites: 3. Characterization of fibre surface coatings and the interphase. Composites 1995 7;26(7):487498.

[35]Liu Y, Shen S, Zhang L, Shao L. X-Ray Photoelectron Spectroscopy Study of Silane Coupling Agents/Basalt Fiber Interface. Advanced Materials Research 2011:1467-1471.

[36]Matuana LM, Balatineez JJ, Sodhi RNS, Park CB. Wood Science \& Technology 1999;35(3):191-201.

[37]Gavrielide A, Duguet T, Esvan J, Lacaze-Dufaure C, Bagus PS. A Poly-Epoxy Surface Explored by Hartree-Fock $\triangle$ SCF Simulations of C1s XPS Spectra . Journal of Chemical Physics 2016;145(7).

[38]Guo X, Yonggen L, Sun Y. Effect of sizing on interfacial adhesion property of glass fiberreinforced polyurethane composites. Journal of Reinforced Plastics and Composites 2017;37(5):321-330.

[39]Calas G, Henderson G, Stebbins JF. Glasses and melts: linking geochemistry and materials science. Elements 2(5), 265-268. Elements 2006;2(5):265-268.

[40]Furukawa T, Brawer S, White WB. The structure of lead silicate glasses determined by vibrational spectroscopy. Journal of Materials Science 1978;13:268-82.

[41]Wang GJ, Liu YW, Guo YJ, Zhang ZX, Xu MX, Yang ZX. Surface modification and characterizations of basalt fibers with non-thermal plasma. Surface and Coatings Technology 2007 4/23;201(15):6565-6568.

[42]Kim MT, Kim MH, Rhee KY, Park SJ. Study on oxygen plasma treatment of a basalt fiber and its effect on the interlaminar fracture property of basalt/epoxy woven composites.

Composites Part B: Engineering 2011;42(3):499-504.

[43]Mittal KL. Polymer Surface Modification: Relevance to Adhesion Vol 3. : CRC Press; 2004.

[44]González-Benito J, Baselga J, Aznar AJ. Microstructural and wettability study of surface pretreated glass fibres. Journal of Materials Processing Technology 199930 August 1999;9293:129-134.

[45]Lee L. Wettability and conformation of reactive polysiloxanes. Journal of Colloid and Interface Science 1968 August 1968;27(4):751-760.

[46]Chen J, Wang Y, Gu C, Liu J, Liu Y, Li M. Enhancement of the mechanical properties of basalt fiber-wood-plastic composites via maleic anhydride grafted high-density polyethylene (MAPE) addition. Materials 2013;6(3):2483-2496.

[47]Khan RA, Khan MA, Zaman HU, Pervin S, Khan N, Sultana S. Comparative studies of mechanical and interfacial properties between jute and E-glass fiber-reinforced polypropylene composites. Journal of Reinforced Plastic Composites 2010;29(7):1078-1088. 
[48]Greco A, Maffezzoli A, Buccoliero G, Caretto F, Cornacchia G. Thermal and chemical treatments of recycled carbon fibres for improved adhesion to polymeric matrix. Journal of Composites Materials 2013;47(3):369-377.

\section{List of figures}

Fig. 1. SEM images of unsized $(N)$ and sized (EP,PPs1-4) fibres indicating topographic changes of the fibre surface

Fig. 2. 3D AFM images of an unsized (N) and sized (EP, PPs1-4) fibre showing topographic changes due to sizing

Fig. 3. Fibre surface roughness ( $\mathrm{Ra}$ and Rrms) and surface area of unsized and sized fibres as measured by AFM

Fig. 4. AFM images of post scratch fibres and resultant scratch depth profile

Fig. 5. High resolution XPS scan of C1s spectra of unsized and sized basalt fibres

Fig. 6. High resolution XPS scan of O1s spectra of unsized and sized basalt fibres

Fig. 7. High resolution XPS scan of Si2p spectra of unsized and sized basalt fibres

Fig. 8. High resolution XPS scan of N1s spectra of PPs1, PPs2 and PPs3 sized basalt fibres

Fig. 9. Static advancing and receding contact angles of unsized and sized basalt fibres in (a) water, and (b) diiodomethane 

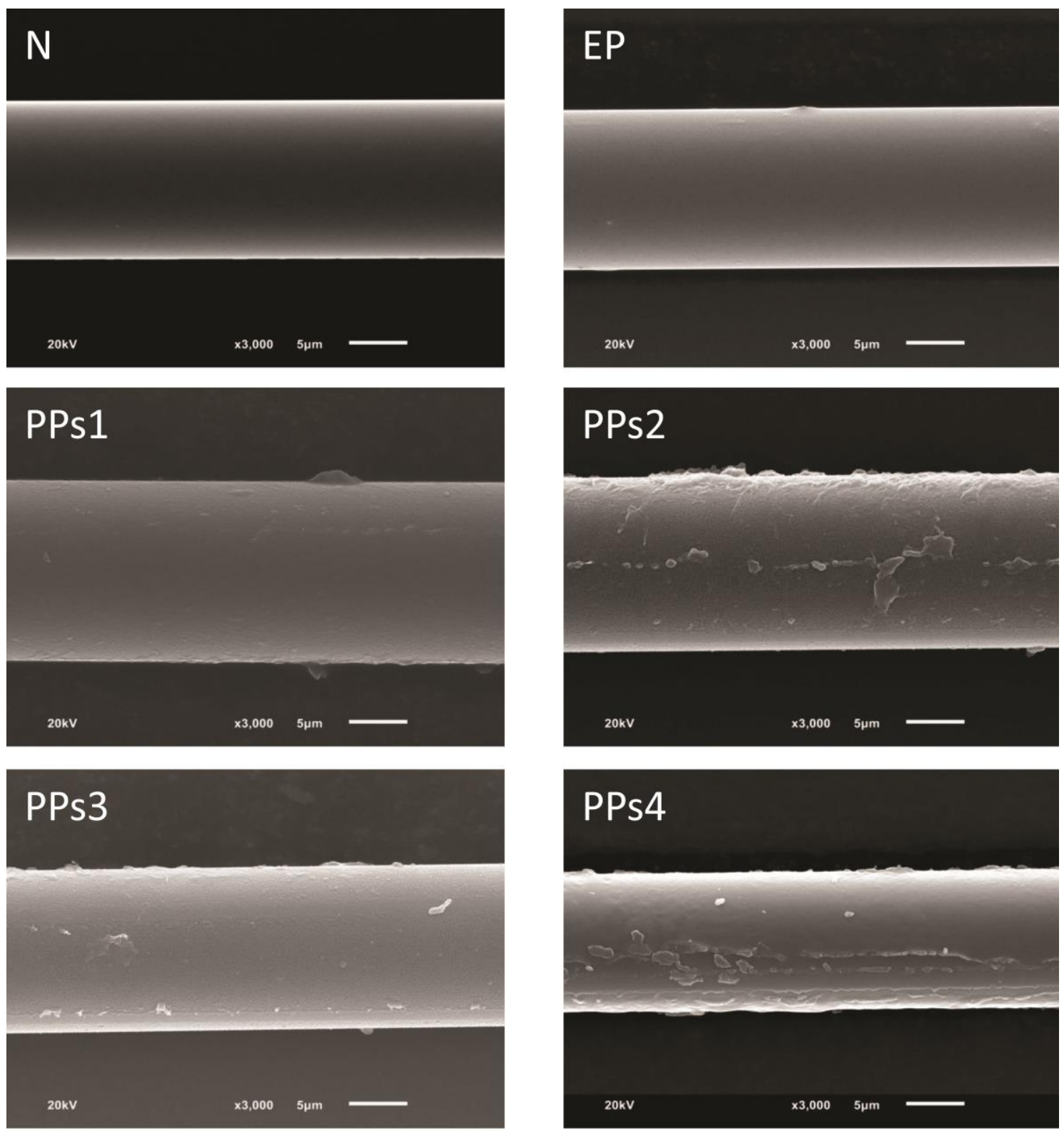

Fig 1. 
N

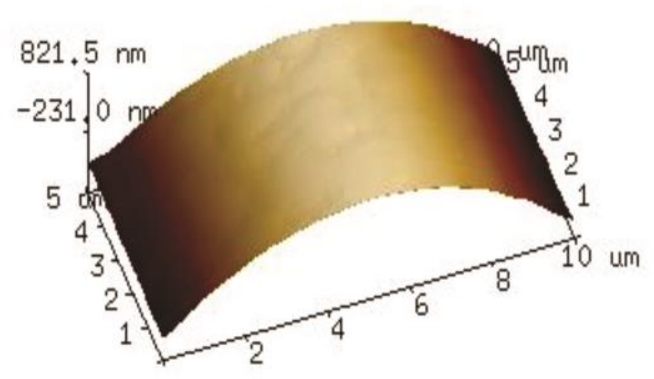

PPs1

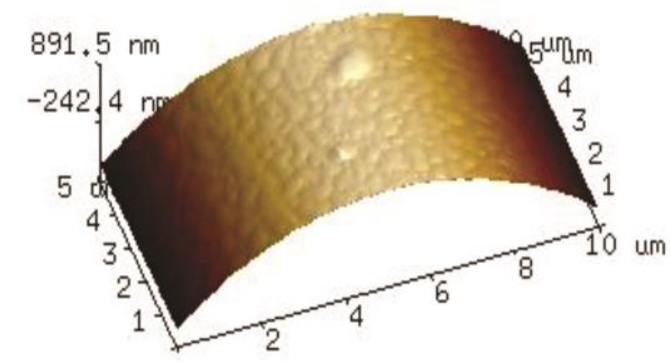

\section{PPs3}

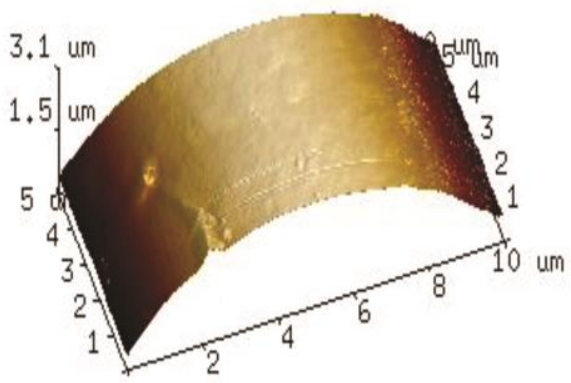

\section{EP}

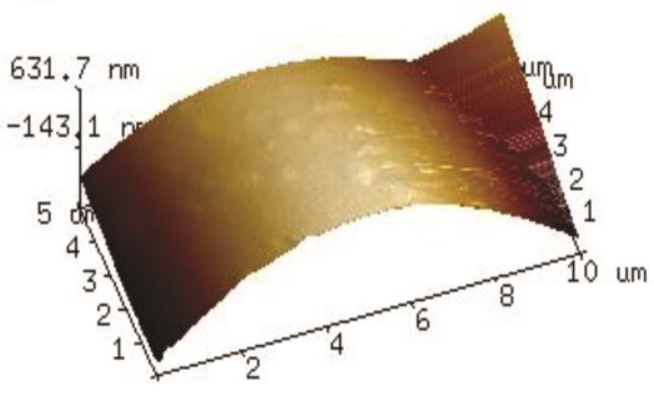

PPs2

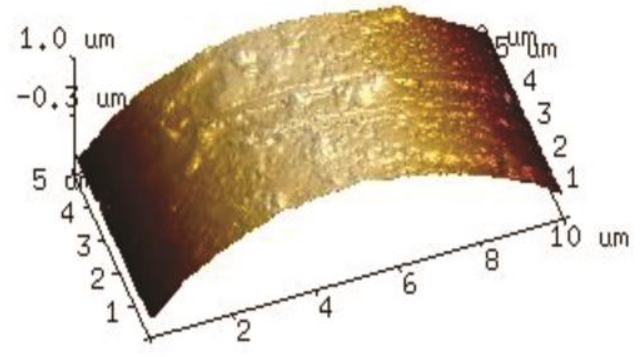

\section{PPs4}

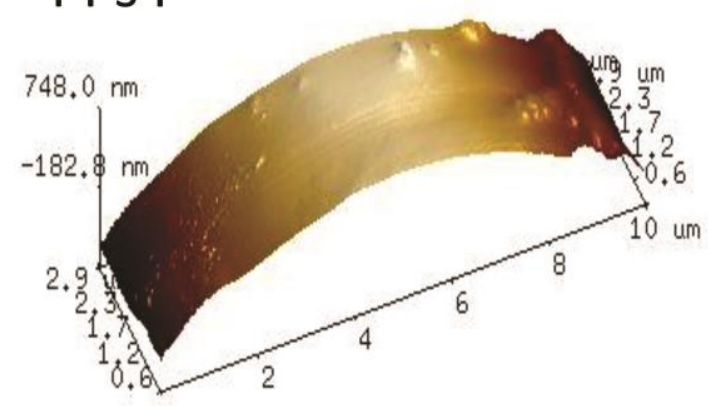

Fig 2. 


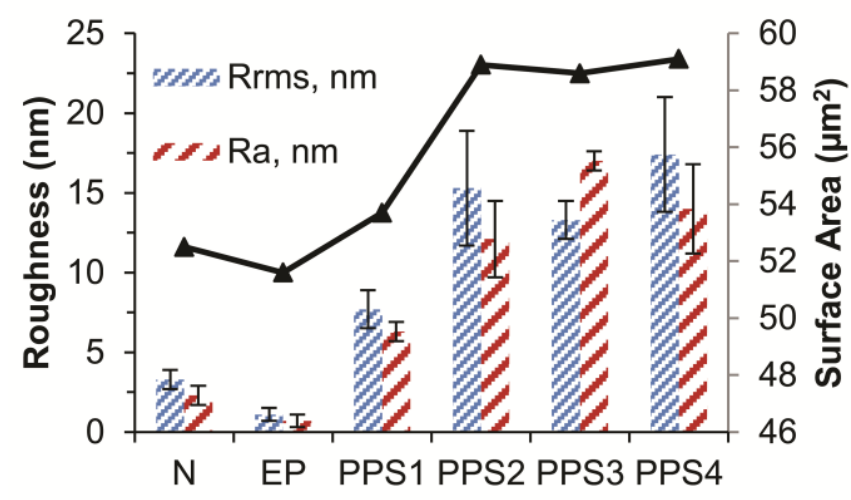

Fig 3. 

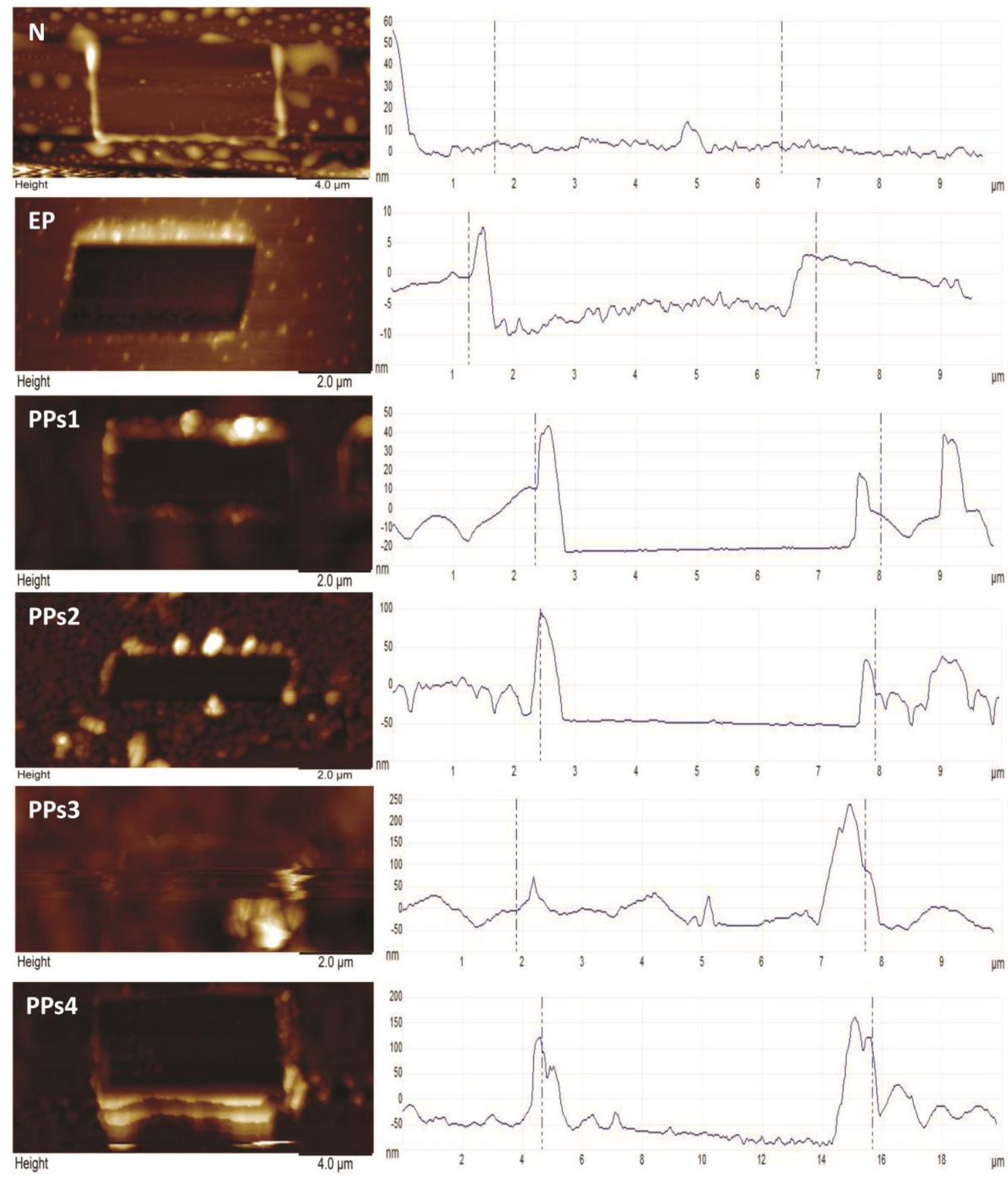

Fig. 4 

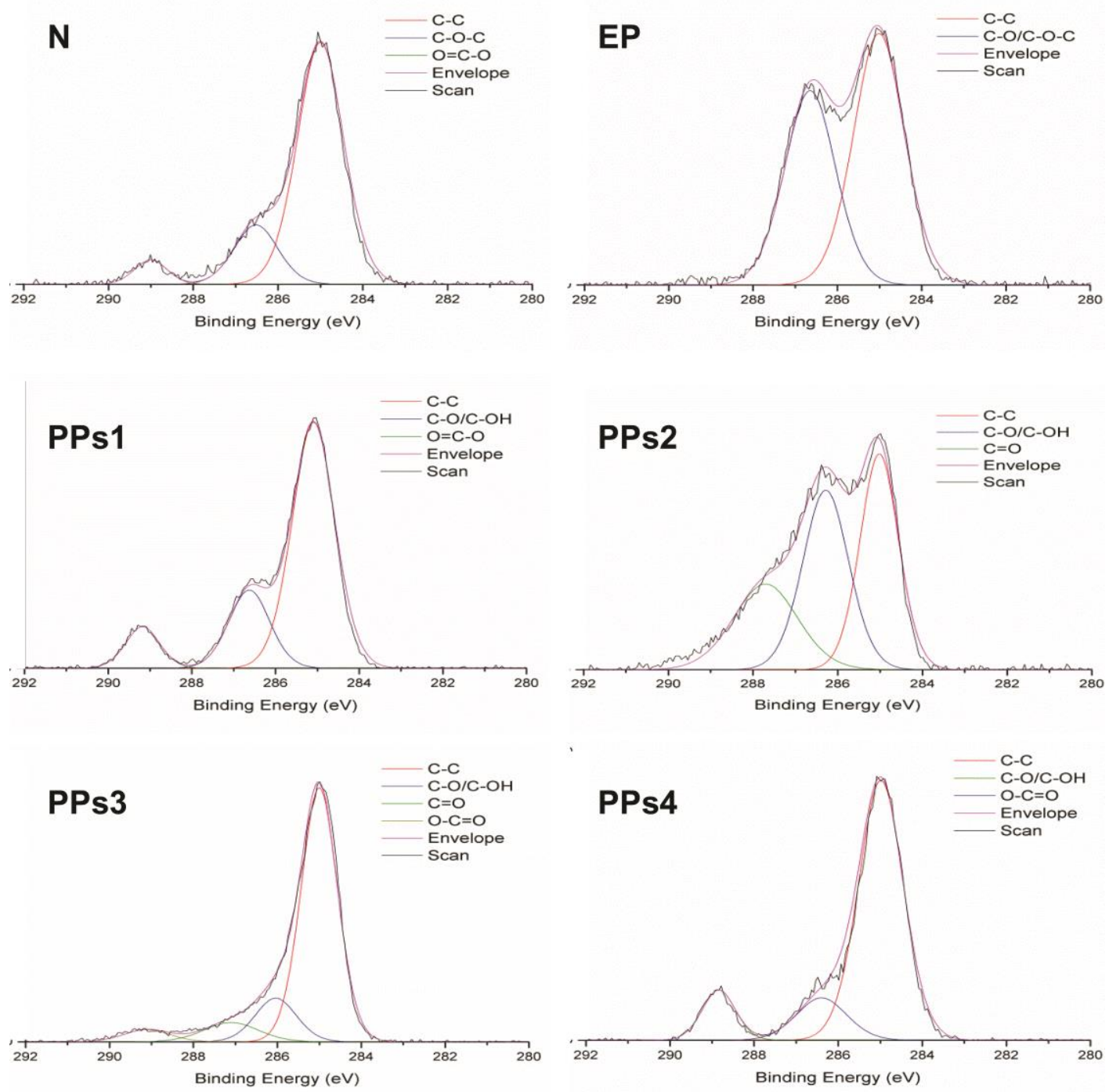

Fig. 5

22 

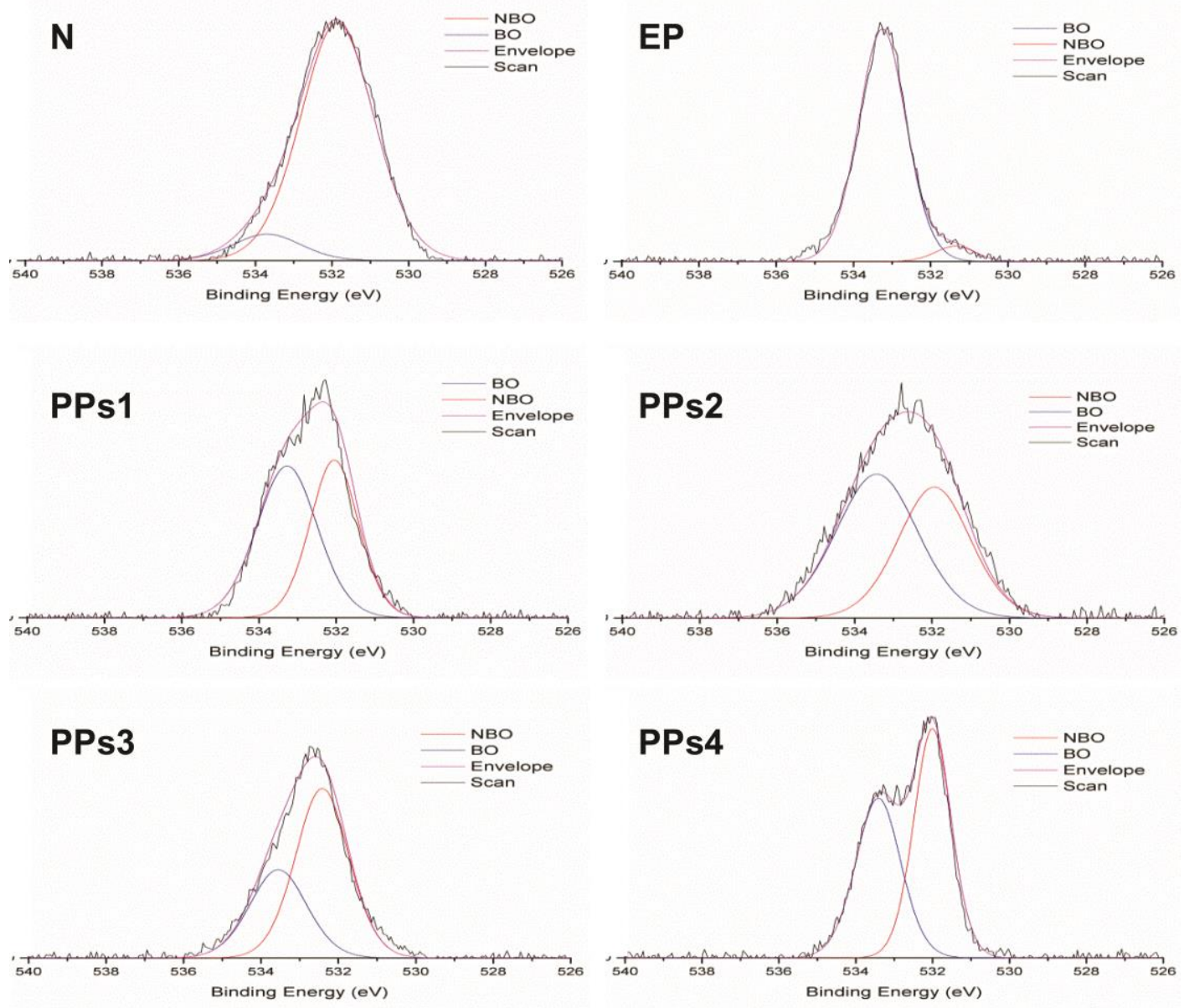

Fig. 6

23 

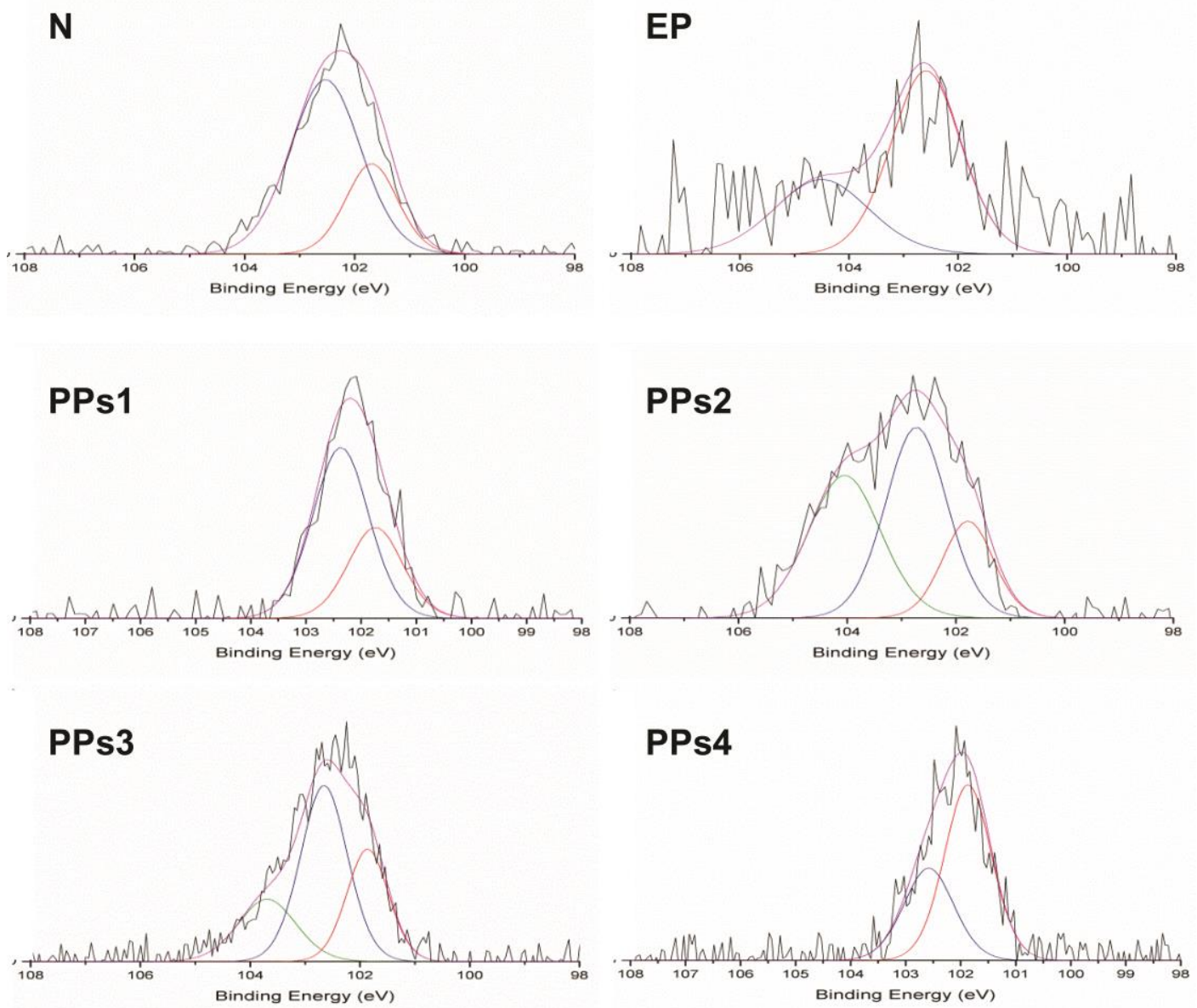

Fig. 7 

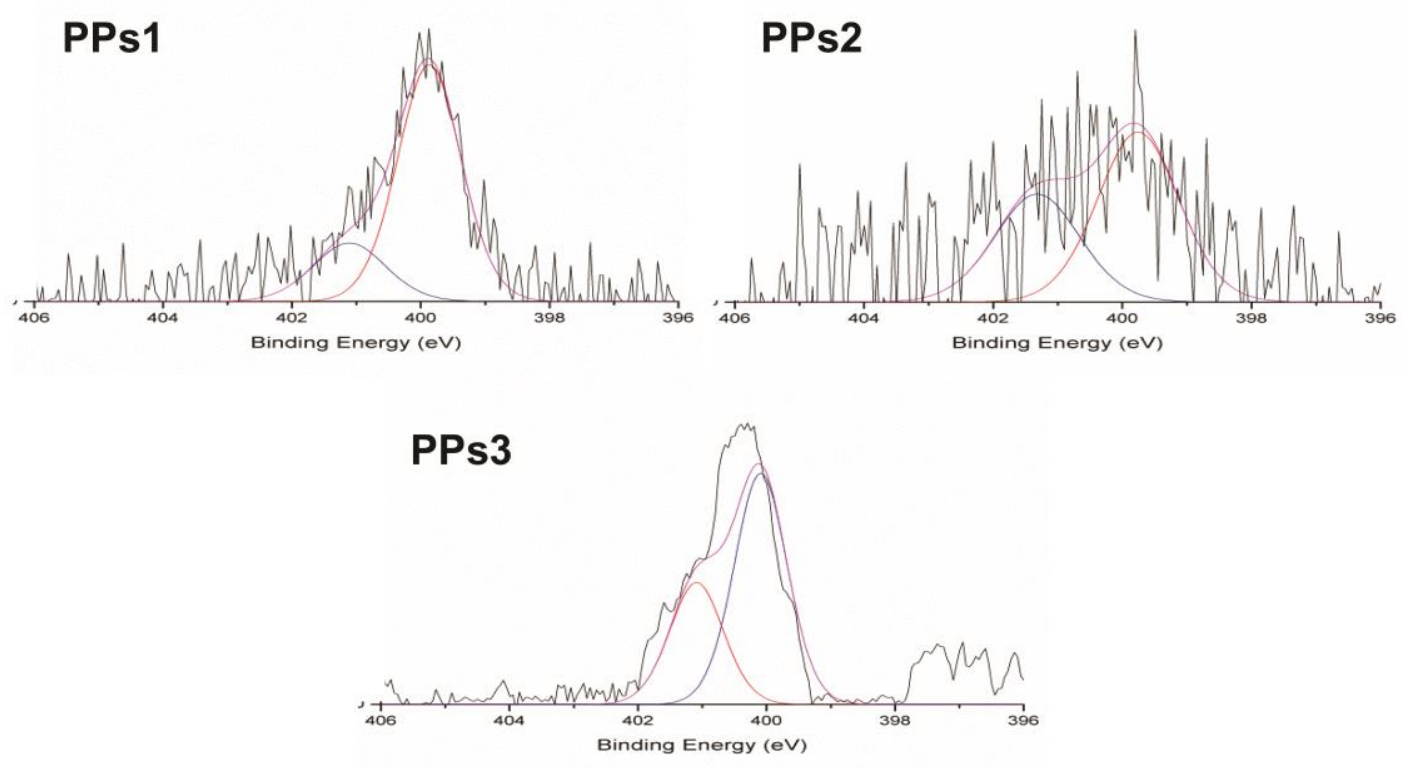

Fig. 8
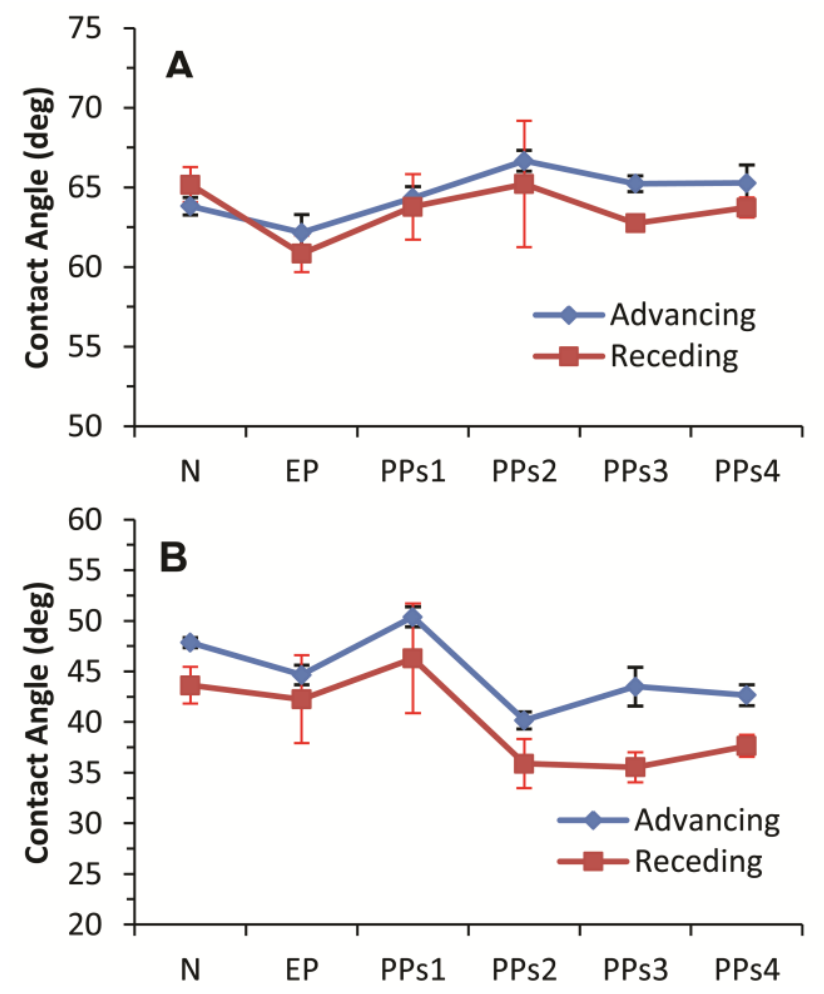

Fig. 9 